\title{
Incidence of Cavum Septum Pellucidum and Cavum Vergae in Dr. Hasan Sadikin General Hospital, Bandung, Indonesia
}

\author{
Ahmad Faried, Adolf Setiabudi Soeprajogo, Regina Melia, Muhammad Zafrullah Arifin
}

Department of Neurosurgery, Faculty of Medicine, Universitas Padjadjaran-Dr. Hasan Sadikin General Hospital

\begin{abstract}
Objective: To describe the cavum septum pellucidum (CSP) and cavum vergae $(\mathrm{CV})$ findings.

Methods: Thirteen samples were recruited in the study. The study was conducted at the Department of Neurosurgery, Dr. Hasan Sadikin Hospital, Bandung, Indonesia in the period of 2015-2016. Thirteen samples were recruited for the study. Cavum septum pellucidum and CV spaces are relatively rare. During neurology and neurosurgery examination of patients with head computed tomography (CT) scan and magnetic resonance imaging (MRI), CSP and CV were discovered accidentally. The incidence of these unique spaces reported from many countries, but have never been reported from Indonesia.
\end{abstract}

Results: This is the first-time reported incidental finding of CSP and CV from Indonesia, 13 cases in one-year period. Since the presence of CSP and CV is usually asymptomatic, clinician seem don't really care to put it in their report.

Received:

December 14, 2016 Conclusions: The presence of CSP and CV as a common incidental finding can

Revised:

March 7, 2017 be more revealed in our country in years to come and hopefully can be more studied in term of anatomical landmark on neurosurgical field.

Accepted:

March 9, 2017

Keywords: Cavum septum pellucidum, cavum vergae, incidental finding

pISSN: 2302-1381; eISSN: 2338-4506; http://doi.org/10.15850/ijihs.v5n1.964 IJIHS. 2017;5(1):42-6

\section{Introduction}

Cavum septum pellucidum (CSP) is an anterior separation of two leaflets of the septum pellucidum resulting the cerebrospinal fluid (CSF)-filled space and usually isolated. It is not a part of the ventricular system and does not communicate with the subarachnoid space; although in some cases communicate with third ventricle. ${ }^{1-3}$ Cavum vergae (CV) is a space that is located as an extention posteriorly of the CSP. The CSP mistakenly referred as the fifth ventricle. The CV does not contain CSF, therefore, it is incorrect to mark $\mathrm{CV}$ as the sixth ventricle. ${ }^{4,5}$ Besides, both CSP and CV are not eqquipped by choroid plexus. The CSP and CV represent normal anatomical variants of ventricle and usually asymptomatic which

Correspondence:

Ahmad Faried, Department of Neurosurgery, Faculty of Medicine, Universitas Padjadjaran-Dr. Hasan Sadikin General Hospital

Jl. Pasteur No. 38, Bandung, Indonesia

e-mail: faried.fkup@gmail.com were commonly found incidentally. ${ }^{2}$

The CSP and CV are developed in utero at 3 months of gestation and begin to fuse from posterior to the anterior or rostral with age, and usually disappear in the first few weeks after birth. Therefore, CSP and CV are present in all premature infants, $97 \%$ at term infants, about $85 \%$ of one month old infants and $12-15 \%$ of six months infant. Meanwhile, the incidence of CSP in full term infants is 36\%. ${ }^{4}$

The CSP may incidentally found alone or together with $\mathrm{CV}$, if both exist then the passage between those two cavities are known as Verga's aqueduct. ${ }^{6}$ The incidence of CSP from various study is ranging from $0.7 \%$ and $37 \%{ }^{4}$ However, the incidence nor observation has never been reported from Indonesia.

\section{Cases}

This study reported several observations of the patients that incidentally seen in their 
imaging (CSP and CV) found in the Department of Neurosurgery, Dr. Hasan Sadikin General Hospital, Bandung, Indonesia.

In the case no 1 , a 66 year-old male came to complain of migrane. The head magnetic resonance imaging (MRI) was performed then CSP and CV spaces were accidentally found.

In the case no 2, a 68 year-old female came with chief complaint of decreased level of conciousness. The symptom was preceded by severe headache and vomiting. The patient was then diagnosed with hypertension five years before admission but did not control blood pressure regularly. The blood pressure was 240/110 mmHg, pulse rate was 108 beat per minute (BPM), Glasgow comma scale (GCS) of E1M4V2, nuchal rigidity was found. The head computed tomography (CT) scan was performed and then CSP and CV were found with hemmorhage. She was diagnosed spontaneous subarachnoid hemorrhage due to suspect aneurysm rupture with intraventricula, -CSP and -CV hemmorhage with emergency hypertension.

In the case no 3 , a 11 year-old boy was complaining of headache since three months prior to admission. Vomitting $(+)$ and gait disturbance was found. Glasgow comma scale was 15 . Romberg test $(+)$, the patients tended to fall to the back. Head CT scan with contrast was performed, CSP and CV were found. The patient was diagnosed non-communicating hydrocephalus due to infratentorial space occupying lession (SOL) ec medulloblastoma.

In the case number 4 , a 10 year-old girl was complaining of headache since one month prior to admission. The patient vomitted $(+)$ and had double vision. Ten days before admission, the patient got seizures at which 3-5 minutes duration each seizure, whole body, before and after seizure patients was concious and GCS was 15 . There were paralysis of left cranial nerve VI and VII central. Head CT scan was performed then CSP and CV spaces were found. The patient was diagnosed with non-communicating hydrocephalus due to colloid cyst at third ventricle.

In the case no 5 , a 58 year-old female came with chief complaint decrease of conciousness. She had history of uncontrolled hypertension. Blood pressure was $170 / 110 \mathrm{mmHg}$, GCS was E3M6V4, and nuchal rigidity was not found. Physiological reflex was normal and there was no pathological reflex. Head CT scan was performed then CSP and CV spaces were found. The patient was diagnosed with spontaneous intracerebellar hemorrhage due to hypertension grade II.

In the case no 6, a 19 year-old male came with chief complaint blindness of both eyes. GCS was 15, pupil round equal with diameter right/left occuli $5 / 5 \mathrm{~mm}$, light reflex right/ left occuli $+/+$, visus right/left occuli 0 , fundoscopy: papil papil atrophy bilateral.

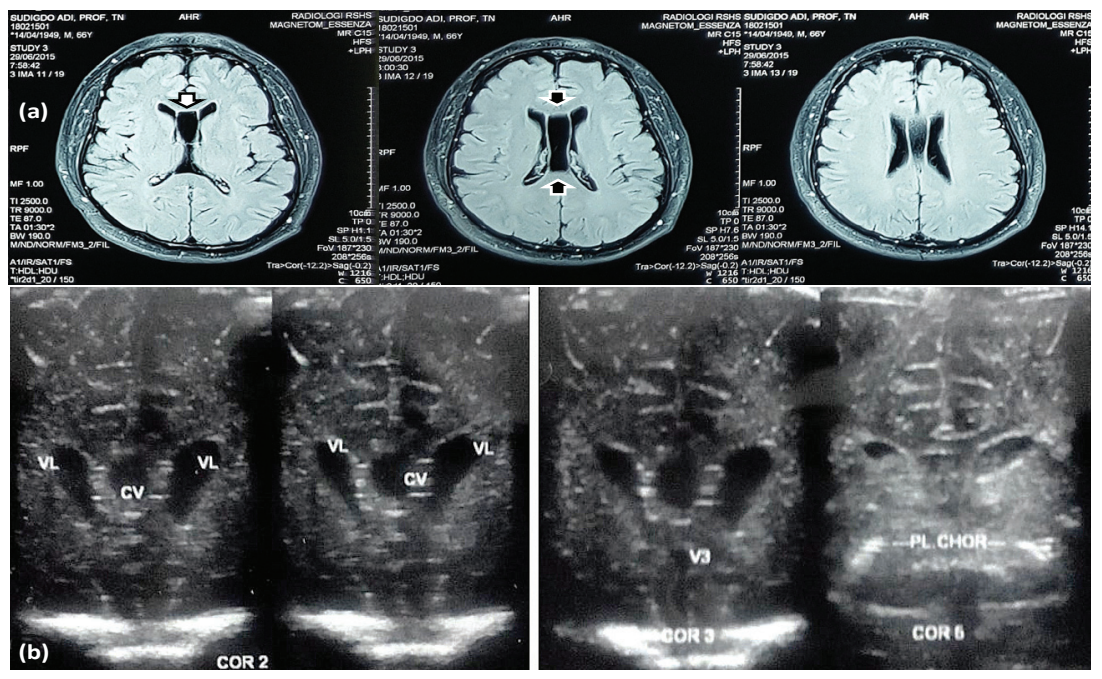

Fig. 1 A 66 Year-old Male with Migrane and Coexistent of Cavum Septum Pellucidum (CSP; White Filled Arrow) and Cavum Vergae (CV; Black Filled Arrow) Observed by Magnetic Resonance Imaging (a). Three Days Old Baby Boy with Ventriculomegaly and CV Observed Using Ultrasonography (b) 
Head CT scan was performed then CSP and CV spaces were found. The patient was diagnosed with supratentorial SOL at sellar region due to hypophysis macroadenoma.

In the case no 7, a 40 year-old female came with chief complaint blindness of both eyes. Glasgow comma scale was 15, pupil round equal with diameter right/left occuli $5 / 5$ $\mathrm{mm}$, light reflex right/left occuli $+/+$, visus right/left occuli 0 , fundoscopy papil atrophy bilateral. Head CT scan was performed, CSP and CV spaces were found. The patient was diagnosed with supratentorial SOL at sellar region due to tuberculum sellae meningioma.

In the case no 8, a 19 year-old female came with chief complaint headache; 4 hours before admission. The patient was riding a motorcycle without helmet suddenly lost her balance and fell down with head hitting the asphalt. Vomiting (+) with GCS was 15. Head CT scan was performed and CSP and CV spaces were found. The patient was dignosed as mild head injury with closed linier fracture at midfrontal and intracerebellar hemorrhage (ICH) at midfrontal at left parietal.

In the case no 9, a 3 day-old baby boy came with ventriculomegaly from ultra sonography (USG). Since ninth month of pregnancy, the neonate was diagnosed with intrauterine ventriculomegaly. As the consequence, the mother was hospitalized and cesarian secton was perfomed, head circumference $34 \mathrm{~cm}(\mathrm{~N}$ : $34-38 \mathrm{~cm}$ ), anterior fontanella open, flat, not tense, $5 \times 4 \mathrm{~cm}$, children comma scale (CCS 11). Ultra sonography transcranial was performed and CV space was found.

Table Summary of Thirteen Patients that Incidentally Found during One Year Period in Dr. Hasan Sadikin General Hospital, Bandung, Indonesia

\begin{tabular}{|c|c|c|c|c|c|}
\hline Age & Gender & Diagnosis & $\begin{array}{l}\text { Imaging } \\
\text { Modality }\end{array}$ & CSP & CV \\
\hline 66 yrs. & Male & Migrane & MRI & $\mathrm{x}$ & $\mathrm{x}$ \\
\hline 68 yrs. & Female & $\begin{array}{l}\text { Spontaneous subarachnoid hemorage due to } \\
\text { rupture aneurysm }\end{array}$ & CT-scan & $\mathrm{x}$ & $\mathrm{x}$ \\
\hline 11 yrs. & Male & $\begin{array}{l}\text { Non-communicating hydrocephalus et causa } \\
\text { infratentorial tumor due to meduloblastoma }\end{array}$ & CT-scan & $\mathrm{x}$ & $\mathrm{x}$ \\
\hline 10 yrs. & Female & $\begin{array}{l}\text { Non-communicating hydrocephalus due to } \\
\text { colloid cyst at 3rd ventricle }\end{array}$ & CT-scan & $\mathrm{x}$ & $\mathrm{x}$ \\
\hline 58 yrs. & Female & $\begin{array}{l}\text { Spontaneous intracerebral hemorage due to } \\
\text { hypertention grade II }\end{array}$ & CT-scan & $\mathrm{x}$ & $\mathrm{x}$ \\
\hline 19 yrs. & Male & $\begin{array}{l}\text { Supratentorial tumor at sella region due to } \\
\text { macroadenoma hipofise }\end{array}$ & CT-scan & $\mathrm{x}$ & $\mathrm{x}$ \\
\hline 40 yrs. & Female & $\begin{array}{l}\text { Supratentorial tumor at sella region due to } \\
\text { tuberculum sellae meningioma }\end{array}$ & CT-scan & $\mathrm{x}$ & $\mathrm{x}$ \\
\hline 19 yrs. & Female & $\begin{array}{l}\text { Mild head injury with closed linear fracture } \\
\text { at midfrontal and intracerebral hemorage at } \\
\text { left parietal }\end{array}$ & CT-scan & $\mathrm{x}$ & $\mathrm{x}$ \\
\hline 3 days old & Male & Intrauterine ventriculomegaly & USG & - & $\mathrm{x}$ \\
\hline 16 yrs. & Female & $\begin{array}{l}\text { Supratentorial tumor at left retroorbita due } \\
\text { to meningioma }\end{array}$ & CT-scan & $\mathrm{x}$ & $\mathrm{x}$ \\
\hline 42 yrs. & Male & $\begin{array}{l}\text { Moderate head injury with intraventricle } \\
\text { hemorage and contusio cerebri at frontal } \\
\text { bilateral et ganglia basal }\end{array}$ & CT-scan & $\mathrm{x}$ & $\mathrm{x}$ \\
\hline 26 yrs. & Female & $\begin{array}{l}\text { Supratentorial cyst at left temporal due to } \\
\text { arachnoid cyst }\end{array}$ & MRI & $\mathrm{x}$ & $\mathrm{x}$ \\
\hline 1 yrs. & Female & Communicating hydrocephalus & CT-scan & - & $\mathrm{x}$ \\
\hline
\end{tabular}

Note: yrs. = years old; CSP = cavum septum pellucidum; CT-scan = computed tomography scan; CV = cavum vergae; $\mathrm{MRI}=$ magnetic resonance imaging; USG = ultrasonography 
In the case no 10, a 16 year-old female came with chief complaint protruded eye. Glasgow comma scale was 15 , pupil round unequal with diameter right/left occuli: $3 / 4 \mathrm{~mm}$, light reflex right/left occuli +/-, visus right/left occuli $+/-$, fundoscopy left papil atrophy. Head CT scan was performed then CSP and CV spaces were found. The patient was diagnosed with supratentorial SOL at left retroorbital due to meningioma.

In the case no 11, a 42 year-old male came with decreased consciousness, 3 hours before admission, the patient was riding a motorcycle with helmet, lost balance, and fell down with head hitting asphalt. Unconsciousness (+), GCS was E3M5V4. Head CT scan was performed and CSP and CV spaces were found. The patient was diagnosed as moderate head injury with IVH and contusio cerebri at frontal bilateral et basal ganglia dextra.

In the case no 12 , a 26 year-old female came with chief complaint vertigo. Glasgow comma scale was 15, head MRI was performed then CSP and CV spaces were found. The patient was diagnosed with supratentorial SOL at left temporal due to arachnoid cyst.

In the case no 13, a 1 year-old baby girl came with head enlargement. Head circumference $58 \mathrm{~cm}$ (N: 44-49 cm), anterior fontanella open, flat, not tense, $7 \times 5 \mathrm{~cm}$, CCS 11, sunset eye $(+)$, frontal boozing $(+)$. Head CT scan was performed and CV space was found. The patient was diagnosed with communicating hydrocephalus.

In this study, the Informed consent was obtained from the patients for publication of this case report and any accompanying images. The patient's family was present at the time.

\section{Discussion}

Septum pellucidum is not simply an anatomical structure having thinned-out translucent membranous that extends from the anterior part or the body, the genu, bridge between the the rostrum of the corpus callosum and the superior surface of the fornix. The septum pellucidum is important relay station linked with the main hippocampus-hypothalamus; part of the limbic system. Therefore, it is septum pellucidum as a correlative center relaying visceral information through hypothalamic autonomic system to hippocampus, amygdala, habenula and brainstem reticular formation, partake in consciousness, sleep and in emotional response to the environment. In this regard, it is a part of the circuit which subserves mental self-maintenance processes, food finding, sexuality, autonomic- vegetative adaptation modes for homeostasis, fight and flight, also species maintenance.

The CSP had been explained in 1851 by an Italian anatomist Andrea Verga and Walter Dandy in 1931 described further regarding the CSP and CV nomenclature. The CSP is a space between the two septum pellucidum anterior to the foramina of monro, when they at least $1 \mathrm{~mm}$ apart. In the anterior, it is bounded by genu and rostrum of corpus callosum (CC), in the posterior it is bound by the fornix, in the superior it is bounded by the body of the CC, and in the inferior by anterior commisure and rostrum of the CC. ${ }^{78}$ Posterior space of foramina of monroe is called a CV. The width of CSP varies from 2-5 mm or more. According to Schwidde, average of transverse, vertical and longitudinal dimensions of CSP is 3,6 , and 7.5 mm. ${ }^{4}$ In the period 10-12 weeks' of gestation, CC starts to develop from the lamina terminalis as a bundel of fiber that connects right and left hemisphere, and cavitation of medial inferior commisural plate of this lamina terminalis will form the leaves of septum pellucidum. Closure of CSP happens at 6-8 months of gestation for rostral to caudal, so it's incidence will decrease as age progress. ${ }^{4,7}$

The prevalence of CSP and CV observed by CT scan is $5.5 \%$ in Great Britain; $1.24 \%$ in China; $0,93 \%$ in Taiwan, but unknown in Indonesia. Cavum septum pellucidum reported might be associated with schizophrenia, post-traumatic stress disorder, chronic brain trauma and boxer. This study did not find such background in the history of the patients. From anatomy point of view, these two cavities are not separated. ${ }^{8-11}$ However, CSP may exist without CV or in opposite manner. Most of our cases (11 out of 13), had both CSP and CV; only two case had only CV; this is an agreement with the previous study by Chen et al. ${ }^{8}$ that found most of their cases had coexistent of CSP and CV $(95.5 \%)$ and CV alone only $1.7 \%$. Theoritically, the prevalence of CSP and CV should decresed as age progresses; in study by Chen et al. ${ }^{8}$ the highest prevalence of CSP and CV are among young adults $\left(20-39\right.$ years old). ${ }^{12}$ However, this study shows that the highest prevalence is among adults ( $>40$ years old; 5 cases) and the lowest is in infants ( 3 days old; one case). This study might not represent the general population in Indonesia and this requires further investigation.

In conclusion, this study is the first reported incidental finding of CSP and CV found in Indonesia which were 13 cases in 
one year period. Since the existance of CSP and CV usually asymptomatic, clinicians seem oblivious relating to this finding. This study discover that the presence of CSP and CV as

\section{References}

1. Bikmaz K, Dinc C, Cakabay M, Iplikcioglu AC. Epidermoid cyst of the cavum septum pellucidum. Acta Neurochir (Wien). 2007;149(1):1271-2.

2. Al-Tubaikh JA, Reiser MF. Congenital diseases and syndrome: an illustrated radiological guide. Berlin Heidelberg: Springer-Verlag; 2009.

3. Greenberg MS. Handbook of neurosurgery. $7^{\text {th }}$ ed. New York: Thieme; 2010.

4. Pearce JMS. Some observations on the septum pellucidum. Eur Neurol J. 2008;59(1):332-4.

5. Ciołkowski MK. Cavum velum interpositum, cavum septum pellucidum and cavum Vergae: A review. Childs Nerv Syst. 2011;27(1):202728.

6. Tubbs RS, Krishnamurthy S, Verma K, Shoja MM, Loukas M, Mortazavi MM, et al. Cavum velum interpositum, cavum septum pellucidum, and cavum Vergae: a review. Childs Nerv Syst. 2011;27(1):1927-30.

7. Winter TC, Kennedy AM, Byrne J, Woodward PJ. The cavum septi pellucidi: why is it important? a common incidental finding can be more revealed in Indonesia in these years to come and hopefully can be more studied in term of anatomical landmark on neurosurgical field.

J Ultrasound Med. 2010;29(1):427-44.

8. Chen JJ, Chen CJ, Chang HF, Chen DL, Hsu YC, Chang TP. Prevalence of cavum septum pellucidum and/or cavum vergae in brain computed tomographies of Taiwanese. Acta Neurol Taiwan. 2014;23(1):49-54.

9. Filipovic B, Ilankovic N, Starcevic A, Filipovic B, Stijak L, Puskas L, et al. Cavum septi pellucidi as a marker of the neuropsychiatric diseases: A pointer or mislead? A cadaveric-clinical observation. J Forensic Res. 2013;5(1):208-12.

10. Aviv RI, Tomlinson G, Kendall B, Thakkar C, Valentine A. Cavum septi pellucidi in boxers. Can Assoc Radiol J. 2010;61(1):29-32.

11. Griffiths PD, Batty R, Reeves MJ, Connolly DJ. Imaging the corpus callosum, septum pellucidum and fornix in children: Normal anatomy and variations of normality. Neuroradiology. 2009;51(1):337-45.

12. Gur RE, Kaltman D, Melhem ER, Ruparel K, Prabhakaran K, Riley M, et al. Incidental findings in youths volunteering for brain MRI research. AJNR Am J Neuroradiol. 2013;34(10):2021-5. 